\title{
Transport of Steroid Hormones through the Rat Blood-Brain Barrier
}

\author{
PRIMARY ROLE OF ALBUMIN-BOUND HORMONE
}

\author{
William M. Pardridge and Lawrence J. Mietus, Department of Medicine, \\ Division Endocrinology \& Metabolism, University of California at Los Angeles \\ School of Medicine, Los Angeles, California 90024
}

\begin{abstract}
A B S T RACT These studies were undertaken to investigate $(a)$ the permeability properties of the bloodbrain barrier (BBB) to the major gonadal and adrenal steroid hormones, and $(b)$ the role of the binding proteins of plasma (albumin and specific globulins) in the regulation of $\mathrm{BBB}$ steroid hormone transport.

The permeability of the BBB to $\left[{ }^{3} \mathrm{H}\right]$-labeled progesterone, testosterone, estradiol, corticosterone, aldosterone, and cortisol, was measured relative to $\left[{ }^{14} \mathrm{C}\right]$ butanol, a freely diffusable reference, in the barbiturate anesthetized rat using a tissue sampling-single injection technique. The isotopes were rapidly injected in a $200-\mu \mathrm{l}$ bolus of Ringer's solution $(0.1 \mathrm{~g} / \mathrm{dl}$ albumin) via the common carotid artery and the percent extraction of unidirectional influx of hormone was determined after a single pass through brain: progesterone, $83 \pm 4 \%$; testosterone, $85 \pm 1 \%$; estradiol, $83 \pm 3 \%$; corticosterone, $39 \pm 2 \%$; aldosterone, $3.5 \pm 0.8 \%$; and cortisol, $1.4 \pm 0.3 \%$. The selective permeability of the BBB was inversely related to the number of hydrogen bonds each steroid formed in aqueous solution and directly related to the respective 1-octanol/Ringer's partition coefficient.
\end{abstract}

When the bolus injection was $67 \%$ human serum, $>95 \%$ of the labeled steroid was bound as determined by equilibrium dialysis. However, the influx of the steroids through the BBB was inhibited by human serum to a much less extent than would be expected if only the free (dialyzable) hormone was transported; progesterone, estradiol, testosterone, and corticosterone transport was inhibited $18,47,70$, and $85 \%$ respectively, or in proportion to the steroid binding to plasma globulins. Rat serum $(67 \%)$ only inhibited the transport of these four hormones, $0,13,12$, and $69 \%$, respectively, reflecting the absence of a sex hormone-binding globu-

Dr. Pardridge is the recipient of Clinical Investigator Award AM-00409.

Received for publication 22 December 1978 and in revised form 16 March 1979. lin in rat plasma. However, neonatal rat serum (67\%) inhibited progesterone, testosterone, and estradiol transport 0,0 , and $91 \%$, respectively, consistent with the presence of an estradiol-binding protein in neonatal rat serum.

The binding of steroid hormone to bovine albumin in vitro (as determined by equilibrium dialysis) was compared to albumin binding in vivo (as determined by the single injection technique). The ratio of apparent dissociation constant in vivo, $K_{D}(\mathrm{app})$, to the in vitro $K_{D}$ was: $\gg 200$ for progesterone, $>200$ for testosterone, 120 for estradiol, and 7.7 for corticosterone. Assuming the steady-state condition, the $K_{D}($ app $) / K_{D}$ was found to be proportional to the BBB permeability for each steroid.

These data demonstrate $(a)$ the selective permeability properties of the BBB to the major steroid hormones is proportional to the tendency of the steroid to partition in a polar lipid phase and is inversely related to the number of hydrogen bond-forming functional groups on the steroid nucleus; $(b)$ the presence of albumin in serum may bind considerable quantities of steroid hormone, but exerts little inhibitory effects on the transport of steroids into brain, whereas globulin-bound hormone does not appear to be transported into brain to a significant extent. Therefore, the hormone fraction in plasma that is available for transport into brain is not restricted to the free (dialyzable) fraction, but includes the larger albumin-bound moiety.

\section{INTRODUCTION}

Unlike other organs, the brain's extracellular space is segregated from plasma by a unique capillary wall (1) i.e., the blood-brain barrier (BBB). ${ }^{1}$ Therefore, circu-

${ }^{1}$ Abbreviations used in this paper: $\mathrm{BBB}$, blood-brain barrier; BUI, brain uptake index; $\mathrm{CBG}$, cortisol-binding globulin; EBP, estradiol-binding protein; $K_{D}$, dissociation constant in 
lating substrates or hormones gain access to brain cells only if such compounds are able to penetrate the BBB. Although quantitative details in regard to the transport of metabolic substrates through the BBB are well known (2), there is a paucity of data in regard to the permeability properties of the BBB to hormonal substances that act on the central nervous system. In particular, the sex steroid hormones (e.g., progesterone, testosterone, estradiol) and the adrenal steroid hormones (e.g., corticosterone, cortisol, and aldosterone) are known to have profound effects on such central nervous system functions as hypothalamic secretions, sex differentiation, and behavior (3). Moreover, specific binding systems for these hormones have been identified in various regions of brain for the gonadal steroids, glucocorticoids (4) and aldosterone (5).

The transport of circulating steroid hormones through the $\mathrm{BBB}$ is complicated by the active binding of these compounds by plasma proteins. More than $98 \%$ of the gonadal steroids are protein bound and $80-90 \%$ of the adrenal steroids are bound by plasma protein (6). Although it is generally regarded that only the free (dialyzable) hormone is transported into tissues such as brain, recent studies have indicated that a variable fraction of albumin-bound ligands such as tryptophan (7) or triiodothyronine (8) are also transported, because of the ability of $\mathrm{BBB}$ binding sites to effectively compete with plasma proteins for binding of the respective ligand. Under these conditions the major plasma moiety of hormone available to brain is the albumin-bound part and not the free (dialyzable) hormone. The objectives of the current study were $(a)$ to investigate the permeability properties of the BBB to the steroid hormones, and $(b)$ to examine the role of the plasma protein in the regulation of the fraction, i.e., free vs. proteinbound, of plasma hormone that is available for entry into brain.

\section{METHODS}

All isotopes were purchased from New England Nuclear, Boston, Mass. The manufacturer specific activities were: D- $\left[1,2,6,7-{ }^{3} \mathrm{H}(\mathrm{N})\right]$ aldosterone, $80 \mathrm{Ci} / \mathrm{mmol} ;\left[2,4,6,7,16,17-{ }^{3} \mathrm{H}\right]-$ estradiol, $143 \mathrm{Ci} / \mathrm{mmol} ; \quad\left[1,2,6,7-{ }^{3} \mathrm{H}(\mathrm{N})\right]$ hydrocortisone, 81 $\mathrm{Ci} / \mathrm{mmol} ;\left[1,2,6,7-{ }^{3} \mathrm{H}(\mathrm{N})\right]$ progesterone, $90 \mathrm{Ci} / \mathrm{mmol} ;[1,2,6,7$, $\left.16,17-{ }^{3} \mathrm{H}(\mathrm{N})\right]$ testosterone, $152 \mathrm{Ci} / \mathrm{mmol} ;\left[1,2,6,7{ }^{3} \mathrm{H}(\mathrm{N})\right]$ corticosterone, $92 \mathrm{Ci} / \mathrm{mmol}$, and $N-\left[1-{ }^{14} \mathrm{C}\right]$ butanol, $1.86 \mathrm{mCi} / \mathrm{mmol}$. All other chemicals were purchased from Sigma Chemical Co., St. Louis, Mo. Fetal calf serum was obtained from Grand Island Biological Co., Grand Island, N. Y.

The radiochemical purity of all isotopes was assessed by thin-layer chromatography with radiochromatogram scanning, and judged to be $>99 \%$ pure, except the $\left[{ }^{3} \mathrm{H}\right]$ testosterone which was $92 \%$ pure. The following solvent systems were used on Silica Gel GF plates (Analtech, Inc., Newark, Del.): aldo-

vitro; $K_{D}(\mathrm{app})$, apparent dissociation constant in vivo; $P C$, Ringer's partition coefficient; $P S$, permeability-surface coefficient; SHBG; sex hormone-binding globulin; $t$, transit time. sterone (cyclohexane 70, chloroform 20, glacial acetic acid 10), testosterone, progesterone, corticosterone, and cortisol (chloroform 85, acetone 15), and estradiol (benzene saturated with formamide). Isotopes were supplied by the manufacturer in a 9/1 benzene/ethanol mixture and this solvent was evaporated before mixing the isotope in Ringer's solution containing 0.1 $\mathrm{g} / \mathrm{dl}$ bovine albumin (nondefatted).

The permeability of the BBB to the labeled steroids was measured by a tissue sampling-single injection technique developed by Oldendorf (9). A 200-300-g male SpragueDawley rat was fed ad lib. on a 12 -h light/dark cycle and studied at 10:00 a.m. each day. The animal was anesthetized with intraperitoneal pentobarbital (Diabutal, $45 \mathrm{mg} / \mathrm{kg}$; Diamond Laboratories, Inc., Des Moines, Iowa), placed in a supine position, and the right common carotid artery was isolated. An $\cong 200-\mu$ l bolus (the exact volume is immaterial) of buffered Ringer's solution ( $\mathrm{pH} 7.4,5 \mathrm{mM}$ Hepes) was rapidly injected via the carotid as a bolus through a sharp 27-gauge needle. The bolus contained $\cong 2-5 \mu \mathrm{Ci} / \mathrm{ml}$ of ${ }^{3} \mathrm{H}$-steroid, $0.5 \mu \mathrm{Ci} / \mathrm{ml}$ of $\left[{ }^{14} \mathrm{C}\right]$-butanol, a freely diffusable internal reference $(10)$, and $0.1 \mathrm{~g} / \mathrm{dl}$ bovine albumin, which was added to insure solubility of the steroid in aqueous solution. The bolus injection prevents mixing of the injection solution with the circulating plasma (9) so that only plasma proteins added to the injection solution influence steroid transport into brain. $15 \mathrm{~s}$ after injection, the animal was decapitated; this period is sufficient for a single pass of the bolus through the brain, but short enough to minimize efflux of label from brain or recirculation of label (11). The cerebral hemisphere ipsilateral to the injection was removed from the cranium and solubilized in $1.5 \mathrm{ml}$ of NCS (Amersham Corp., Arlington Heights, Ill.) by heating to $50^{\circ} \mathrm{C}$ for $2 \mathrm{~h}$ in a metabolic shaker. An aliquot of the injection solution was similarly treated for lipid scintillation counting. After converting counts per minute for each isotope to disintegrations per minute by quench correction, the percent brain uptake index (BUI) was calculated (10):

$$
\mathrm{BUI}=\frac{{ }^{3} \mathrm{H} /{ }^{14} \mathrm{C}(\text { brain })}{{ }^{3} \mathrm{H} /{ }^{14} \mathrm{C}(\text { injection mix })} \times 100 .
$$

By definition, $\mathrm{BUI}=E_{T} / E_{R}(11)$, where $E_{T}$ is the percent extraction of unidirectional influx into brain of the test compound, and $E_{R}$ is the same for the reference compound (butanol). Although butanol is $100 \%$ cleared by brain on a single pass (10), the compound leaves the brain of the anesthetized rat at a rate of $1.1 \% / \mathrm{s}^{2}$ Since the bolus passes through the brain by the first $5 \mathrm{~s}$ after injection (10), there is approximately a $10 \%$ loss of the butanol reference by $15 \mathrm{~s}$ after injection. Therefore, by multiplying the BUI by 0.90 , the BUI may be converted to $E_{T} .{ }^{2}$ Given the rate of whole brain blood flow $(F)$ in the barbiturate anesthetized rat, $0.6 \mathrm{ml} / \mathrm{min}$ per $\mathrm{g}(11)$, the fractional $E_{T}$ may be converted to the BBB permeability-surface product (PS, milliliter per minute per gram) by Crone's equation (12),

$$
P S=-F \ln \left(1-E_{T}\right)
$$

\footnotetext{
${ }^{2}$ If test and reference compounds effluxed from brain back to blood at the same rate, then a correction for reference washout would be obviated. However, recent studies indicate that although butanol molecules in brain freely return to blood, the gonadal steroid hormones (progesterone, testosterone and estradiol) are sequestered by binding systems in brain which impedes their efflux back to blood. (Pardridge, W. M., L. J. Mietus, T. L. Moeller, and W. H. Oldendorf. Kinetics of brain transport and sequestration of blood-borne steroid hormones. Submitted for publication).
} 
where $P S$ is the product of permeability coefficient $(P)$ and the BBB surface area $(S)$.

The permeability coefficients for the various hormones were compared to their lipid solubility as judged by the l-octanol/ Ringer's partition coefficient $(P C)$ for each steroid. The $P C$ was obtained in the following way: $1 \mu \mathrm{Ci}$ of ${ }^{3} \mathrm{H}$-steroid was added to a scintillation vial containing $3 \mathrm{ml}$ of l-octanol and $3 \mathrm{ml}$ of buffered Ringer's solution. The vial was shaken and allowed to equilibrate for $1 \mathrm{~h}$ at room temperature. $2 \mathrm{ml}$ of the octanol layer was then removed and placed in a 7 -ml test tube, followed by the addition of $2 \mathrm{ml}$ of fresh Ringer's solution, and capped with a serum stopper. The tube was shaken and allowed to equilibrate for $1 \mathrm{~h}$ at room temperature. A 20- $\mu \mathrm{l}$ aliquot of the octanol layer was taken for liquid scintillation counting; the tube was then inverted, centrifuged for $10 \mathrm{~min}$ at $1,000 \mathrm{~g}$, and a $300-\mu l$ aliquot of the Ringer's phase was quickly removed via a syringe through the serum stopper; this method (suggested by W. H. Oldendorf, University of California at Los Angeles) prevented contamination by the octanol phase when sampling the denser aqueous phase for isotope activity. The purpose of the first octanol/Ringer's partition was to remove any highly polar impurity in the isotope that might introduce large errors in determination of the $P C$. The calculation of the $P C$ was obtained from the ratio of disintegrations per minute per milliliter in the octanol phase relative to the Ringer's phase.

The saturability of BBB transport of the labeled hormones was investigated by making the final injection solution concentration $25 \mu \mathrm{M}$ in unlabeled hormone; these injection solutions contained a final concentration of $0.45 \mathrm{~g} / 100 \mathrm{ml}$ ethanol.

The effects of various plasma proteins on the transport of labeled steroids into brain was investigated by making the final injection solution $67 \%$ in either rat serum, human (pooled) male serum, neonatal ( $2-3 \mathrm{~d}$ ) rat serum, or fetal calf serum. The neonatal rat serum was obtained by pooling the cervical effluent (after decapitation) from two litters of 2-3-dold unanesthetized pups. The adult rat serum was obtained by aortic puncture of barbiturate-anesthetized animals. In addition, the final injection solution was made $2.5,5$, or $10 \mathrm{~g} / \mathrm{dl}$ bovine albumin (nondefatted).

The free (dialyzable) fraction of labeled hormone in the injection solution containing bovine albumin or human serum was measured by equilibrium dialysis. A $1.5-\mathrm{ml}$ solution of $67 \%$ human serum (pooled male) or $2 \mathrm{~g} / \mathrm{dl}$ bovine albumin in buffered Ringer's solution was mixed with $1.0 \mu \mathrm{Ci}$ of labeled steroid and placed in a dialysis bag made of a $1 \times 20-\mathrm{cm}$ strip of dialyzing tubing. The bag was placed in $15 \mathrm{ml}$ of buffered Ringer's solution ( $\mathrm{pH} 7.4$ ) containing $0.05 \mathrm{~g} / \mathrm{dl}$ sodium azide. Dialysis was done at $37^{\circ} \mathrm{C}$ for $20 \mathrm{~h}$ in a metabolic shaker. Aliquots of buffer and dialysis bag were counted and the fraction of free hormone was calculated from the ratio of disintegrations per minute per milliliter in the buffer divided by the disintegrations per minute per milliliter in the dialysis bag. The albumin dissociation constant $\left(K_{l}\right)$ was calculated from the mass action relationship, $K_{D}=$ (percent-free/percent bound) (albumin concentration), where $2 \mathrm{~g} / \mathrm{dl}$ albumin $=294 \mu \mathrm{M}$, based on $\mathrm{mol} w \mathrm{t}=68,000$.

The albumin $K_{b}$ for each steroid was compared to the apparent $K_{D}$ in vivo $\left(K_{D}\right.$ [app]) as determined with the single injection technique. The differences between albumin binding of a steroid in vivo, i.e., in the presence of a membrane, e.g., the $\mathrm{BBB}$, vs. albumin binding of the ligand in vitro, i.e., in the absence of the membrane, may be depicted as follows:

$$
A L \underset{k_{2}}{\stackrel{k_{1}}{\rightleftharpoons}} A_{F}+L_{F} \stackrel{k_{3}}{\longrightarrow} L_{M}
$$

where $\mathrm{AL}$ is albumin-bound ligand, $A_{F}$ is free albumin, $L_{F}$ is free ligand, $L_{M}$ is transported ligand, $k_{1}$ (per minute) is the rate constant of ligand dissociation from albumin, $k_{2}$ (per minute per molar) is the rate constant of ligand association with albumin, and $k_{3}$ (per minute) is the rate constant of ligand influx into brain. The model assumes firstly, that the dissociation of ligand from albumin must occur before membrane transport of the ligand, and that this dissociation occurs rapidly compared to the mean transit time $(t)$ of plasma flow through brain, i.e., $k_{1} \gg t$. Secondly, the steady-state approximation is made for the albumin-ligand binding reaction, i.e., $d(A L) / d t \simeq 0$, due to $k_{2}\left(A_{F}\right) \gg k_{1}$ or $k_{3}$. Substituting $d(A L) / d t \simeq 0$ into $d(A L) / d t$ $=k_{2}\left(A_{F}\right)\left(L_{F}\right)-k_{1}(A L)$, results in the mass action relationship,

$$
(A L)=\frac{\left(A_{F}\right)\left(L_{F}\right)}{K_{D}}
$$

where $K_{D}=\left(k_{1}\right) /\left(k_{2}\right)$ is the $A L$ dissociation constant in vitro.

The total ligand conservation equation is given by $L_{T}=L_{F}$ $+(A L)+L_{M}$. The expression for $L_{M}$ may be obtained by integrating the rate equation, $d\left(L_{M}\right) / d t=k_{3} L_{F}$. i.e.,

$$
L_{M}=1-e^{-k_{3} t}
$$

where $L_{F}=e^{-k 3 t}$, which is obtained by integrating the rate equation, $d\left(L_{F}\right) / d t=k_{1}(A L)-k_{2}\left(A_{F}\right)\left(L_{F}\right)-k_{3}\left(L_{F}\right)$. Substituting $(A L)$ and $\left(L_{M}\right)$ into the ligand conservation equation for $\left(L_{T}\right)$, and dividing both sides by $(A L)$,

$$
B=\frac{(A L)}{\left(L_{T}\right)}=\frac{A_{F}}{K_{D}\left(e^{k_{3} t}\right)+A_{F}},
$$

where $B$ is the fraction of ligand bound to albumin. The double reciprocal plot (Figs. 7 and 8 ) is

$$
\frac{1}{B}=1+K_{D}(\operatorname{app})\left(\frac{1}{A_{F}}\right),
$$

where $K_{D}(\operatorname{app})=K_{D}\left(e^{k 3 t}\right)$; that is, the apparent albumin dissociation constant in vivo (in the presence of the membrane) deviates from the real $K_{D}$ determined in vitro (in the absence of the membrane) in proportion to $\left(e^{k 3 t}\right)$. If $k_{3} t$ approaches zero, $K_{D}(\operatorname{app})=K_{D}$, as in the in vitro situation. Conversely, the greater $k_{3} t$, e.g., the greater the permeability of the membrane and(or) the greater the transit time, the greater $K_{D}(\mathrm{app})$ will deviate logarithmically from $K_{D}$.

\section{RESULTS}

The BUI for each of the six ${ }^{3} \mathrm{H}$-steroid hormones investigated is shown in Fig. 1. Progesterone, testosterone, and estradiol are nearly completely cleared in a single pass by brain; corticosterone clearance is intermediate, whereas aldosterone and cortisol clearance is low but measureable. The calculated $E_{T}$ values are shown in Table $I$ as are the permeability-surface products for each steroid. The PS estimates for progesterone and testosterone are probably minimum vlaues of $P S$; due to the logarithmic relationship (Methods) between $P S$ and $E_{T}$, compounds with $P S$ values much greater than the rate of cerebral blood flow, will all have about the same $E_{T}$ but may differ markedly in $P S$.

Assuming the capillary surface area in the rat brain is $240 \mathrm{~cm}^{2} / \mathrm{g}(13)$, the $P S$ values may be converted into 


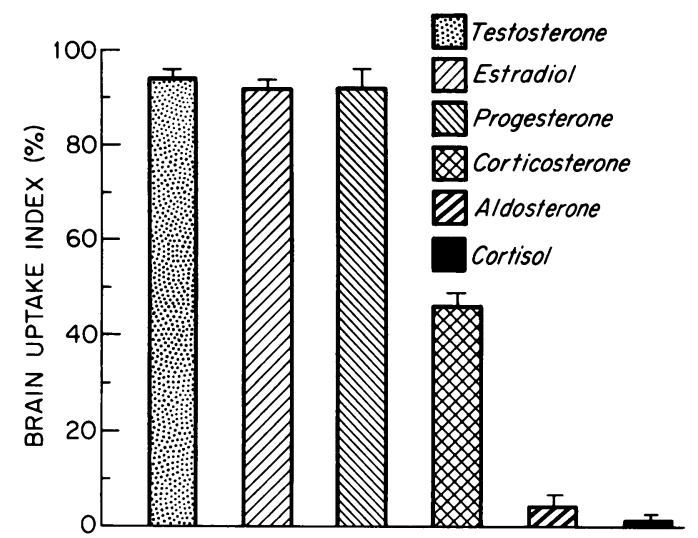

Figure 1 The BUI for six ${ }^{3} \mathrm{H}$-steroid hormones vs. a $\left[{ }^{14} \mathrm{C}\right]-$ butanol reference. Data are means $\pm \operatorname{SEM}$ ( $n=$ four to six rats). The influx of hormones into brain was measured after rapid carotid injection of the compound mixed in buffered Ringer's solution $(\mathrm{pH}=7.4)$ containing $0.1 \mathrm{~g} / \mathrm{dl}$ bovine albumin. The tracer concentration of each hormone in the injection solution: progesterone $(5.6 \mathrm{nM})$, testosterone $(3 \mathrm{nM})$, estradiol $(3.5 \mathrm{nM})$, corticosterone $(14 \mathrm{nM})$, aldosterone $(31 \mathrm{nM})$, and cortisol (123 nM).

permeability coefficients (centimeter per second): progesterone $7.4 \times 10^{-5}$, testosterone $7.9 \times 10^{-5}$, estradiol $7.4 \times 10^{-5}$, corticosterone $2.2 \times 10^{-5}$, aldosterone 1.4 $\times 10^{-6}$, and cortisol $5.8 \times 10^{-7}$. According to Stein (14), the permeability constant of a lipid-soluble compound that penetrates a cell membrane by free diffusion is inversely related to the number of hydrogen bonds the

TABLE I

BBB Permeability, Hydrogen Bond Number, and Octanol/Ringer's PC for the Steroid Hormones

\begin{tabular}{lcccr}
\hline \multicolumn{1}{c}{ Steroid } & $E_{r^{*}}$ & \multicolumn{1}{c}{$P S \downarrow$} & $n \S$ & $P C^{\|}$ \\
\hline & $\%$ & $m l / m i n / g$ & & \\
Progesterone & $83 \pm 4$ & $\geq 1.1$ & 2 & 1,800 \\
Testosterone & $85 \pm 1$ & $\geq 1.1$ & 3 & 530 \\
Estradiol & $85 \pm 3$ & 1.1 & 4 & 196 \\
Corticosterone & $39 \pm 2$ & 0.31 & 6 & 66 \\
Aldosterone & $3.5 \pm 0.8$ & 0.021 & $6-7$ & 12 \\
Cortisol & $1.4 \pm 0.3$ & 0.0084 & 8 & 35 \\
\hline
\end{tabular}

* Percent extraction of unidirectional influx of hormone from blood into brain; $E_{T}=(\mathrm{BUI})\left(E_{R}\right)$, where $E_{R}=0.90$ (Methods). \$ Permeability-surface product: calculated from $E_{T}$ based on whole brain blood flow of $0.6 \mathrm{ml} / \mathrm{min}$ per $\mathrm{g}$ (Methods).

$\S$ The number of hydrogen bonds formed in water based on Stein's formulations (14): 2 for a hydroxyl group, 1 for ketone or aldehyde carbonyl. Aldosterone equilibrates nonenzymically between a hemiacetal form $(n=6)$ and an aldehyde form $(n=7)$.

"The 1-octanol/Ringer's PC. Data are mean of duplicates which were within $95 \%$ reproducibility.
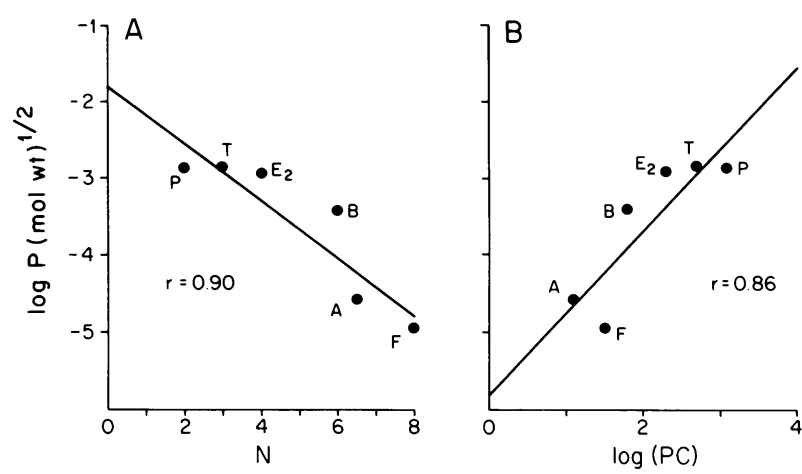

Figure 2 (A) The $\log \mathrm{P}(\mathrm{mol} \mathrm{wt})^{1 / 2}$ for each hormone is plotted vs. the number $(\mathrm{N})$ of hydrogen bonds the steroid makes in aqueous solution; $\mathrm{P}(\mathrm{mol} w \mathrm{w})^{1 / 2}$ is the product of the BBB permeability constant (Table I) times the square root of the molecular weight for each steroid. The $\mathrm{N}$ value (Table I) was assigned according to the rules of Stein (14): 2 for hydroxyl functional groups, 1 for carbonyls of aldehyde or ketone groups, and 0 for ether moieties. (B) The $\log \mathrm{P}(\mathrm{mol} \mathrm{wt})^{1 / 2}$ product is plotted vs. the $\log$ of the 1-octanol/Ringer's $P C$ (Table I), as per the analysis of Hansch and Steward (16). Steroids have been abbreviated as follows: $\mathrm{P}$, progesterone; $\mathrm{T}$, testosterone; $\mathrm{E}_{2}$, estradiol; $\mathrm{B}$, corticosterone; $\mathrm{A}$, aldosterone; F, cortisol.

compound forms in aqueous solution (Table I). In Fig. $2 \mathrm{~A}$, the $\log$ of the permeability constant, normalized for the size of the compound, i.e. square root of the molecular weight (14), is plotted against $\mathrm{N}$, the number of hydrogen bonds formed by each compound. The intercept of Fig. 2A defines the upper limit of BBB permeability (where $\mathrm{N}=0$ ) and is equal to $92 \times 10^{-5} \mathrm{~cm} / \mathrm{s}$ or $13.2 \mathrm{ml} / \mathrm{min}$ per $\mathrm{g}$, if $S=240 \mathrm{~cm}^{2} / \mathrm{g}(13)$ and the molecular weight of the compound is 300 . Other studies $(15,16)$ have indicated the $\log$ of $\mathrm{BBB}$ permeability to lipid-soluble compounds should be proportional to the $\log$ of the octanol/water $P C$; such a relationship is observed in these studies (Fig. 2B). The intercept of Fig. 2B defined the lower limit of BBB permeability, 9.2 $\times 10^{-8} \mathrm{~cm} / \mathrm{s}$, or $0.001 \mathrm{ml} / \mathrm{min}$ per $\mathrm{g}$ if $S=240 \mathrm{~cm}^{2} / \mathrm{g}$ (13) and $\mathrm{mol} w \mathrm{wt}=300$.

To determine whether the transport mechanism was saturable, the BUI of $\left[{ }^{3} \mathrm{H}\right]$-labeled progesterone, testosterone, estradiol, and corticosterone was measured in the presence of a $25-\mu \mathrm{M}$ concentration of each respective unlabeled hormone. The results are shown in Table II and indicate the BBB transport of these compounds is nonsaturable.

Human serum inhibited the influx of progesterone, estradiol, testosterone, and corticosterone, 18, 47, 70, and $85 \%$, respectively (Fig. 3). However, the inhibition by human serum was considerably less than would be expected if only the free (dialyzable) hormone were transported into brain. The free hormone fraction in the human serum injection solution is shown in Table III. If only the free hormone was transported, then the 
TABLE II

Nonsaturability of BBB Transport of Steroid Hormones

\begin{tabular}{lcc}
\hline & \multicolumn{2}{c}{ BUI $^{*}$} \\
\cline { 2 - 3 } Steroid & at tracer concn. & at $25 \mu \mathrm{M}$ concn. \\
\hline & $\%$ & $\%$ \\
Progesterone & $92.0 \pm 4.0$ & $96.6 \pm 3.2$ \\
Testosterone & $94.4 \pm 1.0$ & $95.6 \pm 0.9$ \\
Estradiol & $92.1 \pm 3.9$ & $94.1 \pm 0.5$ \\
Corticosterone & $43.5 \pm 2.4$ & $49.1 \pm 2.4$ \\
\hline
\end{tabular}

* BUI: mean $\pm \operatorname{SEM}(n=$ four to six rats).

inhibition of progesterone, estradiol, testosterone, and corticosterone transport should have been $\cong 95 \%$.

Rat serum inhibited the transport of progesterone, estradiol, testosterone, and corticosterone, $0,13,12$, and $69 \%$, respectively (Fig. 3). The lack of appreciable inhibition of estradiol and testosterone transport by rat serum was consistent with the absence of a sex hormone-binding globulin in this species (17). However, the fetal and neonatal rat has a specific estradiol-binding protein (18) that may be $\alpha$-fetoprotein (19). The effect of $67 \%$ neonatal rat serum on sex steroid transport into brain is shown in Fig. 4; although neonatal rat serum suppressed estradiol transport $91 \%$, there was no effect on the influx of progesterone or testosterone into brain. By comparison, fetal calf serum, which lacks a specific estradiol-binding protein (19), did not show selective effects on estradiol transport, but rather showed a pattern similar to human serum. The influx

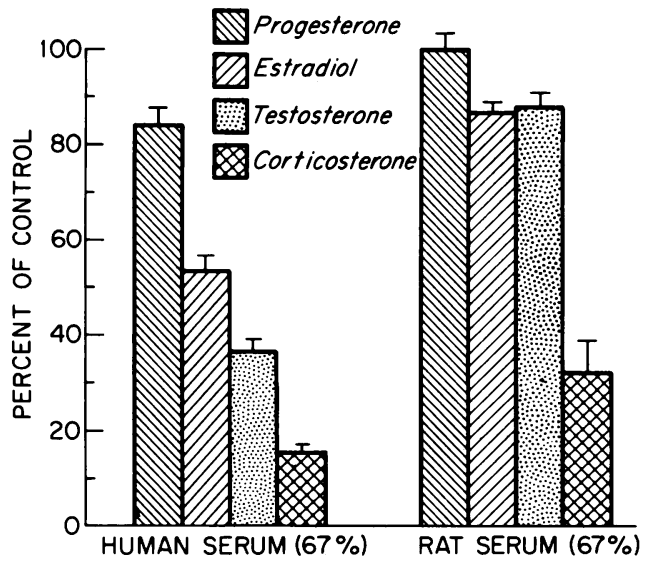

FIGURE 3 The BBB transport of four steroid hormones in the presence of either $67 \%$ human serum (pooled male) or $67 \%$ rat serum (pooled male) is shown as a percent of the BUI value shown in Fig. 1. Data are mean $\pm \operatorname{SEM}$ ( $n=$ four to six rats). Human serum resulted in a statistically significant inhibition for all four steroids shown: progesterone $(P<0.005)$, estradiol $(P<0.0025)$, testosterone and corticosterone $(P<0.0005)$. Confidence limits for the rat serum inhibition: progesterone (NS), estradiol $(P<0.05)$, testosterone $(P<0.005)$, corticosterone $(P<0.0005)$.
TABLE III

Dialyzable Hormone Fraction in 67\% Human Serum

\begin{tabular}{lc}
\hline Hormone $\left({ }^{3} \mathrm{H}\right)$ & Dialyzable* $^{*}$ \\
& $\%$ \\
Progesterone & $2.6 \pm 0.2$ \\
Testosterone & $4.0 \pm 0.1$ \\
Estradiol & $4.7 \pm 0.1$ \\
Corticosterone & $3.1 \pm 0.4$ \\
\hline
\end{tabular}

${ }^{*} \operatorname{Mean} \pm \operatorname{SEM}(n=4)$.

of progesterone, estradiol, and testosterone was inhibited 0,19 , and $44 \%$, respectively by $67 \%$ calf serum.

While the BBB transport of cortisol was too slow to investigate the effects of plasma protein on cortisol transport, such studies could be done with aldosterone. As shown in Table IV, $67 \%$ human or rat serum had no effect on the BBB transport of $\left[{ }^{3} \mathrm{H}\right]$ aldosterone.

The BUI for $\left[{ }^{3} \mathrm{H}\right]$ progesterone in the presence of a carotid injection solution containing 1,5 , and $10 \mathrm{~g} / 100$ $\mathrm{ml}$ bovine albumin is essentially unchanged from the control value (Fig. 5). There is a marked disparity between observed results and what would be predicted if only the free (dialyzable) progesterone was transported (Fig. 5). A similar discordance between observed and predicted results was observed for the transport of testosterone (Fig. 6), estradiol (Fig. 7), and corticosterone (Fig. 8). The lowest concentration of albumin that had a
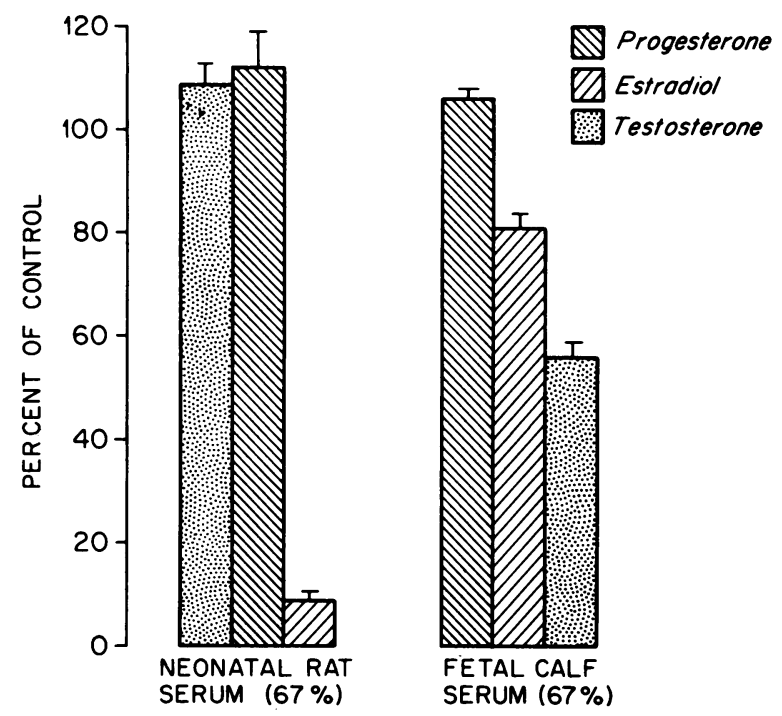

Figure 4 The BBB transport of three sex steroid hormones in the presence of either $67 \%$ neonatal rat serum or $67 \%$ fetal calf serum is shown as a percent of the BUI value shown in Fig. 1. Data are means $\pm \operatorname{SEM}$ ( $n=$ four to six rats). Confidence limits for the neonatal rat serum: progesterone and testosterone (NS), estradiol $(P<0.0005)$, and for the fetal calf serum: progesterone (NS), estradiol $(P<0.05)$, testosterone $(P<0.0005)$. 
TABLE IV

Lack of Inhibition of BBB Transport of Aldosterone by Plasma Protein of Human or Rat Serum

\begin{tabular}{lc}
\hline \multicolumn{1}{c}{ Injection vehicle } & BUI* $^{*}$ \\
\hline & $\%$ \\
Bovine albumin, $0.1 \mathrm{~g} / \mathrm{dl}$ & $3.9 \pm 0.9$ \\
Human serum, $67 \%$ & $3.5 \pm 0.8$ \\
Rat serum, 67\% & $3.7 \pm 0.3$ \\
\hline
\end{tabular}

*BUI: mean $\pm \operatorname{SEM}(n=$ four to six rats).

statistically significant inhibition of $\mathrm{BBB}$ steroid transport was: $5 \mathrm{~g} / 100 \mathrm{ml}$ for testosterone $(P<0.005$, Fig. 6$)$, $2.5 \mathrm{~g} / 100 \mathrm{ml}$ for estradiol $(P<0.025$, Fig. 7$)$, and $5 \mathrm{~g} / 100$ $\mathrm{ml}$ for corticosterone $(P<0.025$, Fig. 8). Alternatively, the results may be expressed as the concentration of albumin, apparent $K_{D}$ or $K_{D}(\mathrm{app})$, that gives $50 \%$ inhibition of steroid transport through the BBB (Table V). The $K_{D}$ values for progesterone and testosterone were estimated from the data in Figs. 5 and 6, and the $K_{D}$ for estradiol and corticosterone were determined from double reciprocal plots (Figs. 7 and 8). Since we measured the $K_{D}$ (Figs. 5-8) of the in vitro hormone binding to the preparation of albumin used in these studies, the $\operatorname{app} K_{D} / K_{D}$ ratio may be calculated (Table V). Based on the model formulated in Methods, the $K_{D}(\mathrm{app}) / K_{D}$ ratio may be related to the rate constant $\left(k_{3}\right)$ of steroid flux through the BBB (Table V).

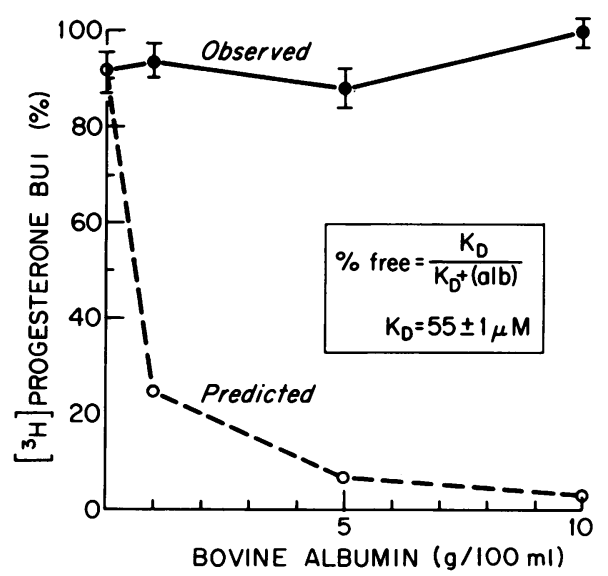

FIGURE 5 The BUI of $\left[{ }^{3} \mathrm{H}\right]$ progesterone is plotted vs. the concentration of nondefatted bovine albumin in the carotid injection solution (observed line). The predicted line represents the inhibition expected if only the free (dialyzable) hormone was transported, and was calculated from the product of the control BUI ( $y$-intercept) times the percent free hormone at each albumin concentration. The percent free hormone was calculated from the law of mass action, knowing the dissociation constant $\left(K_{D}\right.$, determined by equilibrium dialysis) and the albumin molarity (based on $\mathrm{mol} \mathrm{wt}=68,000$ ). Data are mean $\pm \operatorname{SEM}(n=3-4)$.

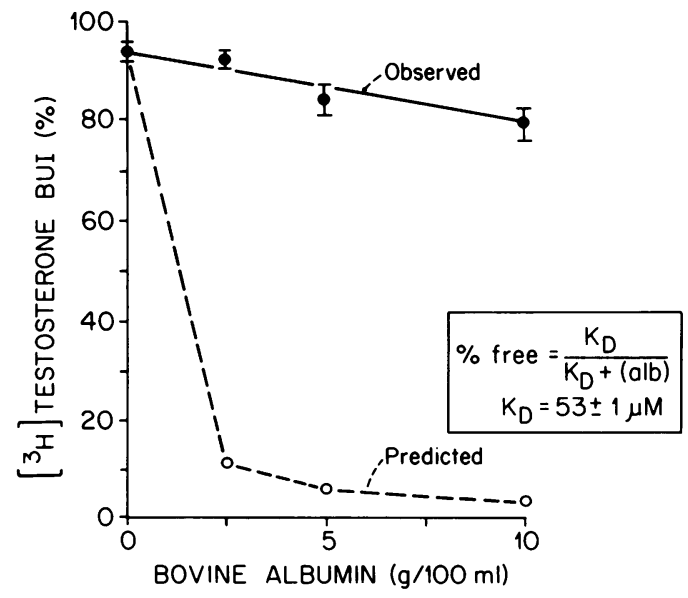

Figure 6 The BUI of $\left[{ }^{3} \mathrm{H}\right]$ testosterone is plotted against the concentration of bovine albumin in the carotid injection solution. See legend to Fig. 5 for details.

\section{DISCUSSION}

These studies document $(a)$ the selective permeability properties of the $\mathrm{BBB}$ to the major steroid hormones, and $(b)$ the in vivo competitive interactions between binding of a steroid hormone to a plasma protein vs. transport of the hormone through a biological membrane, the BBB. These latter results may have important clinical implications.

The basis to the selective permeability of the BBB to the steroid hormones appears to be related to the lipid solubility of the compound and the tendency of the steroid to form hydrogen bonds in water. The correlation between membrane permeability and the octanolRinger's partition coefficient is reasonably linear (Fig. 2). However, the number of hydrogen bonds formed by the steroid in aqueous solution is also a limiting factor and in the case of cortisol seems to overrule the correlation between membrane permeability and lipid solubility. As shown in Table I, cortisol is threefold more soluble in octanol than is aldosterone. However, the transport of cortisol through the BBB is less than half that of aldosterone, apparently due to the greater tendency of cortisol to form hydrogen bonds (Table I) with water $(n=8)$ as opposed to aldosterone $(n=6-7)$. If the $n$ value is predictive of BBB permeability, then steroid compounds such as estrone $(n=3)$, or the adrenal androgens, dehydroepiandrosterone $(n$ $=3)$ and $\Delta^{4}$-androstenedione $(n=2)$ might be expected to readily penetrate the $\mathrm{BBB}$. The correlation between BBB permeability and lipid solubility or hydrogen bonding, together with the nonsaturability of steroid transport (Table II), are evidence in favor of the steroids penetrating the BBB by free diffusion. However, a receptor-mediated transport mechanism of low affinity, but high capacity, cannot be excluded on the basis of the existing data. 


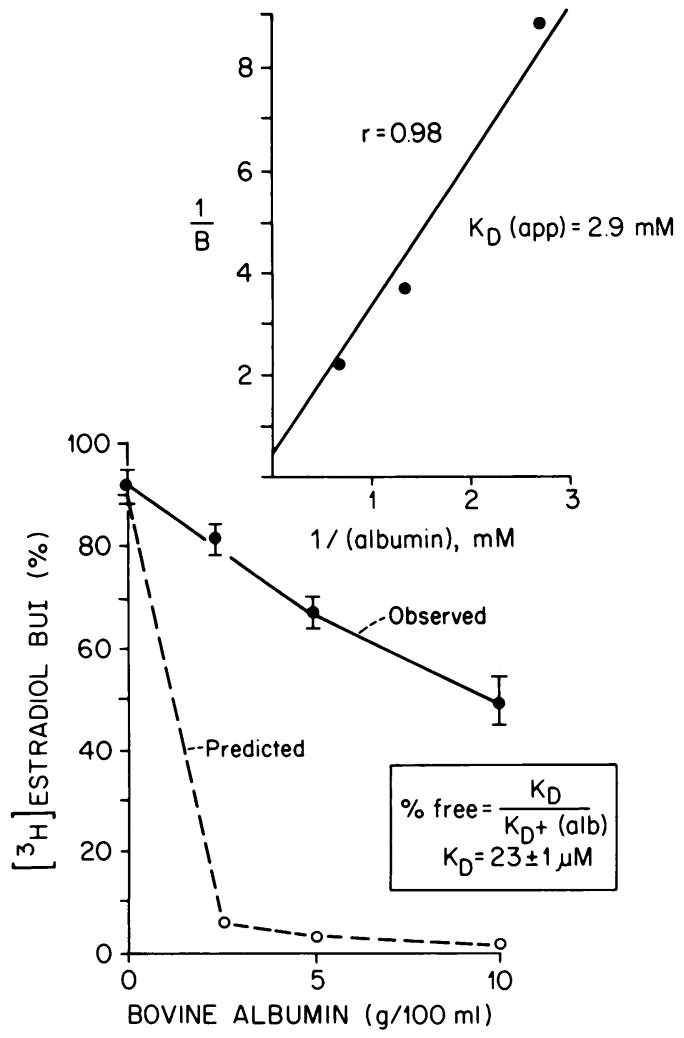

FIgURE 7 The BUI of $\left[{ }^{3} \mathrm{H}\right]$ estradiol is plotted vs. the concentration of bovine albumin in the carotid injection solution. See legend to Fig. 5 for details. The $K_{D}(\mathrm{app})$ is calculated from the slope of a double reciprocal plot (Methods). The fraction of steroid bound to albumin at the capillary level was determined from the fractional inhibition of steroid transport by albumin, i.e., $\mathrm{B}=\left(\mathrm{BUI}_{0}-\mathrm{BUI}\right) /\left(\mathrm{BUI}_{0}\right)$, where $\mathrm{BUI} \mathrm{I}_{0}$ and $\mathrm{BUI}$ refer, respectively, to the uptake in the absence of albumin and in the presence of albumin. Details of a similar kinetic analysis have been described previously (17).

In addition to characterizing the selective permeability properties of the $\mathrm{BBB}$, the single bolus injection technique allows the investigation of the effects on steroid transport of the various plasma proteins which actively bind the hormones. Generally the steroid hormones are partitioned between a low affinity, high capacity site (albumin) and a high affinity, low capacity binding site (steroid-binding globulin). The globulins are specific for classes of hormones; a sex hormonebinding globulin (SHBG) binds testosterone and estradiol and occurs in such species as primates and ruminants but not rodents (17). The presence of SHBG in man and calf, but not the rat, correlates with the measurable inhibition of testosterone and estradiol transport by human and fetal calf serum, but weak inhibition by rat serum (Figs. 3 and 4). The glucocorticoids, corticosterone and cortisol, are bound to a cortisol-binding globulin (CBG) (6), and this protein is present in virtually all vertebrates except

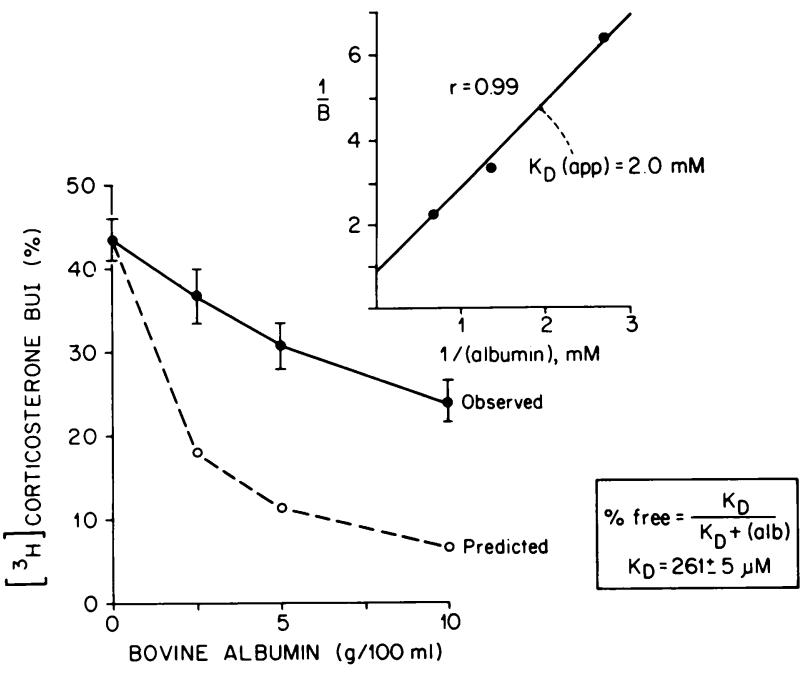

FigURE 8 The BUI of $\left[{ }^{3} \mathrm{H}\right]$ corticosterone is plotted against the albumin concentration in the carotid injection solution. See legends to Figs. 5 and 7 for details.

amphibians and fish (17). Similarly, both rat and human serum had marked inhibitory effects on the BBB transport of corticosterone (Fig. 3). Although adult rat serum lacks SHBG (17), fetal and neonatal rat serum (18) contain estradiol-binding protein (EBP), a globulin which may actually be $\alpha$-fetoprotein (19). Due to the high concentration, about $50 \mu \mathrm{M}$ (18), of EBP in neonatal rat serum (which is $\cong 1,000$-fold the concentration of SHBG in human serum), the binding by neonatal rat serum of estradiol is enormous (18), and essentially all of the estrogen would be expected to be bound to EBP and very little to albumin. This is consistent with the very slight uptake of estradiol by brain in the presence of neonatal rat serum (Fig. 4). Since EBP does not bind testosterone (18), this hormone enjoys free access to the

TABLE V

Comparison of Albumin Binding of Steroid Hormones In Vitro vs. In Vivo

\begin{tabular}{lcccr}
\hline \multicolumn{1}{c}{ Steroid } & $\begin{array}{c}K_{D}{ }^{*} \\
\text { (in vitro) }\end{array}$ & $\begin{array}{c}K_{D}(\text { app }) ! \\
\text { (in vivo) }\end{array}$ & $K_{D}($ app $) / K_{D}$ & $k_{3}{ } \S$ \\
\hline Progesterone & $\mu M$ & $m M$ & & \\
Testosterone & 55 & $\gg 10$ & $\gg 200$ & $>5.3$ \\
Estradiol & 53 & $>10$ & $>200$ & $>5.3$ \\
Corticosterone & 23 & 2.9 & 120 & 4.8 \\
& 261 & 2.0 & 8 & 2.0 \\
\hline
\end{tabular}

* Determined by equilibrium dialysis (Figs. $5-8$ ); $K_{D}=$ albumin-steroid dissociation constant.

$\ddagger$ Determined by carotid injection technique (Figs. 5-8). $\S$ Calculated from $\ln \left\{K_{D}(\mathrm{app}) / K_{D}\right\}=k_{3} t$ (Methods); $k_{3}=$ rate constant (per second) of steroid flux through the BBB and $t=$ mean capillary transit time. The respective $k_{3}$ for each steroid is proportional to the $P S$ value (Table I). 
brain in the presence of neonatal rat serum (Fig. 4). These results are consistent with existing concepts of sex differentiation in the newborn rat brain (20), i.e., testosterone freely enters brain and is converted to estradiol, whereas circulating estrogens do not enter brain due to the high activity of EBP. Although calf serum contains SHBG (17), the $\alpha$-fetoprotein of fetal calf serum lacks the characteristics of EBP (19). Therefore, the effect of fetal calf serum on steroid transport is more analogous to human rather than neonatal rat serum (Fig. 4).

Whereas the binding of steroid to specific globulins correlates with the percent inhibition of steroid transport, the extent to which a steroid hormone is bound to albumin appears to underlie the degree to which the steroid is transported into brain. For example, progesterone has a very low affinity for SHBG (21) and is primarily bound to albumin or other unassigned low affinity sites $(6,22) ;^{3}$ virtually all of the blood progesterone is cleared by brain (Figs. 3 and 4), despite the fact that only $3 \%$ of the plasma progesterone is free (Table III). Similarly, nearly all of estradiol and testosterone is albumin bound in the rat (17) and nearly all of the plasma estradiol and testosterone is cleared by brain (Fig. 3). In man, however, only $\cong 40$ and $60 \%$ of testosterone and estradiol are respectively bound to the albumin fraction of male serum (23); similarly $\cong 40$ and $60 \%$ of testosterone and estradiol are transported into brain (Fig. 3). The greater transport of estradiol, i.e., greater binding to albumin relative to testosterone is due to the lower affinity of SHBG for the estrogen $(21,23)$. In regard to albumin binding of the corticosteroids, the $K_{D}$ of albumin binding of the glucocorticoids, $\cong 300 \mu \mathrm{M}(6)$, is much higher than the albumin $K_{D}, \cong 25 \mu \mathrm{M}(6)$, for the sex steroids. Consequently albumin binding of the corticosteroids is relatively weak and only $\cong 15 \%$ of these compounds are albumin bound (22). Similarly only $15 \%$ of corticosterone is transported into brain in the presence of human serum (Fig. 3). Aldosterone is bound mainly to albumin in vivo (6), and is transported into brain without inhibition by plasma proteins (Fig. 5).

The quantitative analysis of the albumin inhibition data (Figs. 5-8) is dependent on the validity of the steady-state assumption (Methods), such that $d(A L) / d t$ $\simeq 0$ during the course of the bolus transit through the brain, $\cong 2 \mathrm{~s}(24)$. Given this simplifying assumption, an explicit relationship is obtained between the in vivo albumin binding, represented by $K_{D}$ (app), and the in vitro albumin binding, represented by $K_{D}$, i.e. In $K_{D}(\operatorname{app}) / K_{D}=k_{3} t$, where $k_{3}$ is the rate constant of steroid

\footnotetext{
${ }^{3}$ Although progesterone has a high affinity for CBG, the free cortisol level in serum approximates the $K_{D}$ of CBG for cortisol, which raises the app $K_{D}$ of CBG for progesterone such that only a small fraction of progesterone is CBG-bound in vivo (6).
}

flux through the BBB and $t$ is the capillary transit time. However, the condition that $d(A L) / d t$ is exactly equal to zero is clearly not obtained with the single injection technique used in the present studies. The concentration of the $A L$ complex falls with time as the bolus traverses the capillary and ligand is transported out of the bolus and into brain. However, as reviewed by Wong (25), the steady-state approximation does not require that $d(A L) / d t=0$ be obtained exactly; the steady-state assumption only requires that $d /(A L) / d t$ be slow compared to the rate of $A L$ formation, which is equal to $k_{2} A_{F} L_{F}$. That is, the rate of $A L$ formation must exceed the rate of $A L$ loss due to membrane transport, which is given by $k_{3} L_{F}$ (Methods). The assumption that $k_{2}\left(A_{F}\right)>k_{3}$ may be tested as follows: given a minimum value for steroid-protein association constants, $k_{2}=10^{6} / \mathrm{M}$ pers $(26)$, and $A_{F}=0.5 \mathrm{mM}(3.4 \mathrm{~g} / \mathrm{dl})$, the product, $k_{2} A_{F}$, is at least $500 / \mathrm{s}$. Estimates of $k_{3}$ may be made from the data in Table $V$; assuming the capillary transit time, $t=1 \mathrm{~s}$, then the $k_{3}$ for estradiol is about $5 / \mathrm{s}\left(\mathrm{t}_{1 / 2}=150 \mathrm{~ms}\right)$, or 100 -fold less than the $k_{2} A_{F}$ product. Therefore, the greater rate of ligand reassociation with albumin vs. transport of ligand through the $\mathrm{BBB}$ insures that $d(A L) / d t \simeq 0$. However, the fact that the $A L \rightleftharpoons A_{F}+L_{F}$ cycle occurs many times per second (see below) will eventually lead to substantial transport of the albumin-bound ligand. Therefore, the binding reaction probably passes through a continuous succession of steady states during bolus flow through the brain. Similar quasi-steady-state models have been proposed for hepatic transport processes studied with either the constant infusion or the single injection technique (27).

The observation that, at a physiologic concentration of albumin, $80-100 \%$ of albumin-bound steroid hormone is transported through the BBB (Figs. 5-8), but globulin-bound hormone does not appear to be transported to any significant extent (Figs. 3 and 4), is consistent with the model (Methods) that ligand dissociation into the free state is prerequisite to transport of protein-bound ligand through the membrane. The selectivity between transport of albumin-bound or globulin-bound steroid probably derives from the relationship between the rate of unidirectional ligand dissociation $\left(k_{1}\right)$ from the protein vs. the capillary transit time. It is known that SHBG-bound testosterone or estradiol unidirectionally dissociates at $37^{\circ} \mathrm{C}$ at a rate of 3 and $10 \% / \mathrm{s}$, respectively (28); CBG-bound cortisol unidirectionally dissociates at $37^{\circ} \mathrm{C}$ at a rate of $5 \% / \mathrm{s}$ (29). Since the bolus transit time through the rat brain is only $2-3 \mathrm{~s}(24)$, the mean capillary transit time is about $1 \mathrm{~s}$, i.e., a period too short for globulin-bound steroid to dissociate. ${ }^{4}$ Albumin-bound steroid, how-

\footnotetext{
${ }^{4}$ Although the capillary transit time in a peripheral organ such as brain is only $\cong 2 \mathrm{~s}(24)$, the transit time in liver,
} 
ever, probably unidirectionally dissociates with a halftime of milliseconds. Whereas precise data are not known in regard to albumin dissociation times, it is known that the affinity of albumin for steroids is $>1,000$ fold less than the specific globulin, as shown by the 1,000-greater $K_{D}$ for albumin relative to the globulin binding of steroid hormones (6). Because $k_{1}$ is generally proportional to $K_{D}$ for ligand-protein interactions (26), the indirect data suggest the rate of ligand dissociation from albumin is extremely fast relative to the transit time.

Finally, the observation that albumin-bound hormone is readily transported through the $\mathrm{BBB}$ indicates this fraction of plasma hormone is the major part available to peripheral tissues such as brain; in all cases, the percent of albumin-bound hormone, $60 \%$ progesterone, $60 \%$ estradiol, $40 \%$ testosterone, and $15 \%$ corticosteroid, is severalfold greater than the free (dialyzable) fraction, 2-8\%, of total plasma hormone $(6,22,23)$. Since both the fraction of dialyzable hormone and albumin-bound hormone will vary inversely with the level of binding globulin in plasma, the dialyzable fraction will generally be directly related to the percent of albumin-bound hormone and thus be directly related to brain clearance of the hormone. However, it must be emphasized that the dialyzable fraction is relatively small, indeed, in some cases trivial, compared to the albumin-bound moiety of circulating steroid hormone.

\section{ACKNOWLEDGMENTS}

The authors are grateful for many valuable discussions with Doctors William H. Oldendorf, Josiah Brown, and Andre Van Herle. Charlotte Limberg provided outstanding secretarial assistance.

These studies were supported by the National Science Foundation (BNS 78-05500).

\section{REFERENCES}

1. Brightman, M. W. 1977. Morphology of blood-brain interface. Exp. Eye Res. 25(Suppl): 1-25.

2. Pardridge, W. M., and W. H. Oldendorf. 1977. Transport of metabolic substrates through the blood-brain barrier. $J$. Neurochem. 28: 5-12.

3. Challis, J. R. G., F. Naftolin, I. J. Davies, K. J. Ryan, and T. Lanman. 1976. Endogenous steroids in neuroendocrine tissues. In Subcellular Mechanisms in Reproductive

owing to the unique capillary anatomy, is quite long, e.g., $\cong 10$ s (30). The prediction that due to the long transit time in liver, globulin-bound steroid may be transported into liver cells, has recently been confirmed with a portal vein injection technique (31). Over $70 \%$ of progesterone, testosterone, estradiol, aldosterone, and cortisol is unidirectionally cleared by liver cells and only the transport of testosterone is inhibited by the plasma protein in human serum. (Pardridge, W. M., and L. J. Mietus. 1979. Transport of proteinbound steroid hormones into liver in vivo. Am. J. Physiol. 237: In press.
Neuroendocrinology. F. Naftolin, K. J. Ryan, and J. Davies, editors. Elsevier/North Holland, Amsterdam. 247-261.

4. McEwen, B. S. 1976. Steroid receptors in neuroendocrine tissues: topography, subcellular distribution, and functional implications. In Subcellular Mechanisms in Reproductive Neuroendocrinology. F. Naftolin, K. J. Ryan, and J. Davies, editors. Elsevier/North Holland, Amsterdam. 277-304.

5. Ermisch, A., and H-J. Ruhle. 1978. Autoradiographic demonstration of aldosterone-concentrating neuron populations in rat brain. Brain Res. 147: 154-158.

6. Westphal, U. 1971. Steroid-Protein Interactions. SpringerVerlag New York, Inc., New York.

7. Pardridge, W. M. 1977. Kinetics of competitive inhibition of neutral amino acid transport across the blood-brain barrier. J. Neurochem. 28: 103-108.

8. Pardridge, W. M. 1979. Carrier-mediated transport of thyroid hormones through the rat bloodbrain barrier: primary role of albumin-bound hormone. Endocrinology. 105: In press.

9. Oldendorf, W. H. 1970. Measurement of brain uptake of radiolabeled substances using a tritiated water internal standard. Brain Res. 24: 372-376.

10. Oldendorf, W. H., and L. D. Braun. 1976. $\left({ }^{3} \mathrm{H}\right)$ Tryptamine and ${ }^{3} \mathrm{H}$-water as diffusible internal standards for measuring brain extraction of radio-labeled substances following carotid injection. Brain Res. 113: 219-224.

11. Pardridge, W. M., and W. H. Oldendorf. 1975. Kinetics of blood-brain barrier transport of hexoses. Biochim. Biophys. Acta. 382: 377-392.

12. Crone, C. 1965. Facilitated transfer of glucose from blood into brain tissue. J. Physiol. (Lond.). 181: 103-113.

13. Ohno, K., K. D. Pettigrew, and S. I. Rapoport. 1978. Lower limits of cerebrovascular permeability to nonelectrolytes in the conscious rat. Am. J. Physiol. 253(3): H299-H307.

14. Stein, W. D. 1967. The Molecular Basis of Diffusion Across Cell Membranes. Academic Press Inc., New York. 65- 124.

15. Oldendorf, W. H. 1974. Lipid solubility and drug penetration of the blood brain barrier. Proc. Soc. Exp. Biol. Med. 147: $813-816$.

16. Hansch, C., and A. R. Steward. 1964. The use of substituent constants in the analysis of the structure-activity relationship in penicillin derivatives. $J$. Med. Chem. 7: $691-694$.

17. Corvol, P., and C. W. Bardin. 1973. Species distribution of testosterone-binding globulin. Biol. Reprod. 8: 277-282.

18. Raynaud, J-P., C. Mercier-Bodard, and E. E. Baulieu. 1971. Rat estradiol binding plasma protein (EBP). Steroids. 18: 767-788.

19. Alpert, E. 1978. Human alpha-fetoprotein (AFP) developmental and biological characteristics. In Prevention of Neural Tube Defects: The Role of Alpha Feto Protein. B. F. Crandall and M. A. B. Brazier, editors. Academic Press Inc., New York. 19-26.

20. Naftolin, F., K. J. Ryan, and I. J. Davies. 1976. Androgen aromatization by neuroendocrine tissues. In Subcellular Mechanisms in Reproductive Neuroendocrinology. F. Naftolin, K. J. Ryan, and J. Davies, editors. Elsevier/ North Holland, Amsterdam. 347-355.

21. Mickelson, K. E., and P. H. Petra. 1978. Purification and characterization of the sex steroid-binding proteins of rabbit serum. Comparison with the human protein. J. Biol. Chem. 253: 5293-5298.

22. Rosenthal, H. W., W. R. Slaunwhite, Jr., and A. A. Sandberg 1969. Transcortin: A corticosteroid-binding protein of plasma. X. Cortisol and progesterone interplay and un- 
bound levels of these steroids in pregnancy. J. Clin. Endocrinol. Metab. 29: 352-367.

23. Vermeulen, A. 1977. Transport and distribution of androgens at different ages. In Androgens and Antiandrogens. L. Martini and M. Motta, editors. Raven Press, New York. 53-65.

24. Furlow, Jr., T., and N. H. Bass. 1976. Cerebral hemodynamics in the rat assessed by a non-diffusible indicatordilution technique. Brain Res. 110: 366-370.

25. Wong, J. T. 1975. Kinetics of enzyme mechanisms. Academic Press, Inc., New York. 10-11.

26. Westphal, U. 1978. Steroid-binding globulins: recent results. In Receptors and Hormone Action. B. W. O'Malley and L. Birnbaumer, editors. Academic Press, Inc., New York. 2: 443-472.

27. Keiding, S., S. Johansen, K. Winkler, K. Tonnesen, and N.
Tygstrup. 1976. Michaelis-Mentin kinetics of galactose elimination by the perfused pig liver. Am. J. Physiol. 230: $1302-1313$.

28. Heyns, W., and P. De Moor. 1971. Kinetics of dissociation of $17-\beta$-hydroxysteroids from the steroid binding $\beta$-globulin of human plasma. J. Clin. Endocrinol. Metab. 32: $147-154$.

29. Dixon, P. F. 1968. The kinetics of the exchange between transcortin-bound and unbound cortisol in plasma. J. Endocrinol. 40: 457-465.

30. Goresky, C. A. 1970. The interstitial space in liver: its partitioning effects. In the 2nd Alfred Benzon Symposium on Capillary Permeability, Copenhagen. 415-430.

31. Pardridge, W. M. 1977. Unidirectional influx of glutamine and other neutral amino acids into liver of fed and fasted rat in vivo. Am. J. Physiol. 232: E492-E496. 